$$
\begin{aligned}
& 1 A E A-5 M-146 / 13 \\
& \text { CONF-700810-- }
\end{aligned}
$$

EVALUATION OF POTENTIAL HAZARDS FROM TRITIUM WATER

\title{
Environmental Aspects of Nuclear Power Stations
}

Ney York City

10-14 August 1970

\section{Brookhaven National Laboratory \\ Upton, I. I., N. Y.}

\section{REGLL NOTICE}

LEGAL NOTHCE This report was prepared the United States Government. Ntates Atomic Energy This rared by the Unithe United States Aes, nor any of spontared United States nor the theis employees, nor anyloyees, the United star nor any of theis ers or theis employes, Commission, nor any subcontractors, or thet assumes any their contractors, subcontess or implied, ox acuracy, commakes any warranty, expribility for the accus apparatus, Isal liability or respon of any intormationts that its use pleteness or useruss disclosed, of represents 
Evaluation of Potentia? Hazards from Tritium Water*

V. P. Bond

Tritium is produced by reactors, as a ternary fission product and as a result of neutron interaction with coolant additives, deuterium and other reactor components. Some of the tritium is released to the énvironment in the form of tritiated water (HTO), from the reactor itself and from fuel reprocessing plants. Although tritium has a long half life, and is dispersed in the biosphere with relative ease, the calculated dose (dose equivalent) to the public from reactor-produced HTO is relatively quite small for the present and the next several decades (see below). Thus, altiough HTO and its possible effects must receive continuing detailed attention, it would appear to present no significant hazard to the public unless the calculated dose does not adequately reflect its toxicity.

The purpose of the present paper is to review the various factors that must be considered in evaluating the toxicity of tritium in the form of tritiated water (KTO). The conclusion is reached that values of dose equivalent for tritium, as calculated by $\operatorname{MCRP}-\operatorname{ICRP}$ formulae $(1,2)$ give a conservative and adequate assessment of the potential hazard. from this isotope. A given dose of radiation to an organ from the beta rays of tritium has the same radiobiological meaning as the given dose from $x-r a y s$ or gamna rays (same dose rate pattern), and no significant added hazard is to be attached by virtue of the fact that the dose may have been derived from tritium.

The potential hazards of the radiation from tritium are estimated basically, as in the case of any lonizing radiation, in terms of the ab-

* IAEA Symposium, "Evaiuation of Potential Hazarda from Tritium Water". New York City, Augunt 1970. 
sorbed dose in rads. Maximum permissible "doseq", or MPD's (more precisely, maximum permissible dose equivalents) are expressed in terms of rem, i.e., the dose in rads multiplied by a quality factor, (QF). The maximum permissible body burden (MPBB) of an isotope is the amount of activity, e.g., microcuries, that, having gained access to the body, will deliver an MPD to a given organ or organs. Maximum permissible concentrations (MPC's) of radioactive isotopes, e.g., in water or air, are expressed in units of activity per unit volume, e.g., microcuries per cubic centimeter, and are based on the amount of activity that, with a stated rate of exposure, will lead to an MPBB or MPD to a given organ or organs $(1,2)$.

The several factors that must be considered in determining the toxicity of HTO are discussed separately below, following which an overall evaluation is given. Estimates of dose to the public that may result from HTO released from nuclear power and reprocesing plants are also given.

The Absorbed Dose in Rads. Tritium decays by beta emmission only, with a physical half life of 12.26 years. The maximum energy of the beta ray is $18 \mathrm{kev}$ and its average energy is approximately $6 \mathrm{kev}$. Tritium in the environment is encountered almost entirely in the form of tritiated water. With a single exposure resulting from the breathing or ingestion of HTo, the isotope distributes rapidly and fairly uniformly throughout the body.

The absorbed dose from tritium is calculated in the same maner as the dose from any isotope, and the calculation involves basically the following formula: 
$D=k A E$

Where

$D=$ absorbed dose rate in rads per unit time

$A=$ activity, in terms of disintegrations per minute, microcuries - or other suitable units

$E=$ average energy of the tritium beta ray, and

$k=\mathbf{a}$ constant.

Since the energy of the beta from tritium is among the lowest of any isotope encountered practically, the dose in rads, for a given total number of disintegrations per unit mass of tissue, is less than that from any other isotope.

The Dose Equivalent in rem; $R B E$ and $Q F$. For radiation protection purposes, the "dose" (technically, the "dose equivalent") of radiation is expressed in terms of rem, arrived at as follows:

$D E=(D)(Q F)$

Where

$D E=$ dose equivalent in rem

D = absorbed dose in rads

$Q F=$ quality factor, equivalent in concept to the $R B E$, or the relative biological effectiveness.

The QF and RBE depend upon the quality of radiation, commonly expressed in terms of linear energy transfer, or LET. Because the beta rays from tritium are of relatively low energy, they might be thought of as roughly equiralent to the "end of the tracks" of beta rays of higher energy, and the possibility exists that the $R B E$ for the tritium beta rays might thus be greater than one $(3,4)$. Some experimental evidence has appeared to be consistent with an RBE (and QF) in excess of 1.0 and a $A F$ of 1.7 was used for many years for radiation protection purposes $(1,2)$. Precise RBE values for tritium beta radiation are difficult to determine, particularly 
in the mammal. Recently the pertinent biological material has been reviewed $(5-10)$, and there appears to be little convincing evidence that the RBE is significantly different from unity. The ICRP has recently revised its evaluation, and is in the process of recommending that a QF of 1.0 , rather than 1.7 , be used (11). Thus there appears to be little or no basis for ascribing higher toxicity to tritium on the basis of radiation quality and $R B E$.

Body Distribution and Excretion of HTO. Following the exposure to HTO through either breathing or ingestion, the isotope distributes rapidly, essentially as body water, i.e., almost uniformly throughout the body. It is excreted rapidly, and the biological or effective half time for escretion in man of approximately 12 days $(1,2)$ is a major determining factor with respect to the amount of radiation exposure received.

Tritium in vivo is e:schangeable with hydrogen, and can in principle replace hydrogen on any biochemical compound $(5,12,13)$. Also, in metabolic processes, tritium from tritiated water can be incorporated into nonexchangeable position in biological molecules including carbohydrates, . proteins, RWA and DNA $(5-8,12-18)$. These facts were well known when current exposure limits for $\mathrm{H}^{3}$ were established in $1959(1,2)$, and pertinent references dating back to 1951 were listed (1). With a single exposure the amounts metabolically incorporated into organic compounds may be less than $2 \%(5,12)$. With long-term exposure under extreme conditions in which the organism receives essentially all of its water intake from sources with a given concentration of tritium, organically bound tritium in tissue solids will range from $1 \%$ to $2 \%$ up to as much as $35 \%$ of the concentration maintained in the intake water $(14,16)$. 
Thus the rate of excretion of tritium will depend upon the duration of exposure. The excretion pattern may be regarded as the sum of exponentials $(5,14,19,20)$. Data in man indicate that the excretion rate may be represented as three exponentials, with half times of disappearance of approximately 6,23 and 345 days (19). Thus the half time of disappearance, of 12 days used by the $\operatorname{ICRP}$ and $\operatorname{NCRP}(1,2)$ may represent an "effective" rate of excretion.

Possible Cuncentration of Tritium in Organs. Certain isotopes are known to be selectively retained and thus become relatively concentrated in certain body tissues, e.g., the thyroid has an affinity for fodine. By this process, the concentration of iodine in the thyroid can be many times greater than the concentration of iodine in other organs. Other examples of such selective retention and concentration are well-known, and are taken into account in the calculation of absorbed dose to body organs, in the calculation of maximum permissible concentration (MPC's) of radiosctive species in air and water $(1,2)$, and in the calculation of dose to indiViduais in specific stuations.

Such a concentration phenowenon for tritium, if it occurs at all in the mammal, would be expected to be seen with aingle or repeated exposures to tritium. Animal studies show the reverse (5, 6, 14-18). In one experiment $(5,15)$, in mice given tritiated water cver a five month period, the concentration of tritium in tissues ranged from approximately 0.1 to $10 \%$ (eleven tissues) of that in the body water.

Apparent exceptions have occurred in which the concentration of tritium in some organs in mammals in the wild state have appeared to be higher thain that in the plasma $(21,22)$. However, the previous history of these animals could not be doctimenced, and the animals did have access 
to sources of tritium at higher concentrations than those in their plasma water. Under these circumsiances the data do not permit one to conclude that a true concentration factor is involved. The apparent tissue concentration is most probably derived from the fact that animals had been ingesting tritium from high concentration sources, and then had changed to lower concentration sources in the environment before being sampled. At any rate, the apparent concentration factor did not exceed approximately $1,4$.

The possibility of some concentration of tritium under unusual circumstances cannot be dismissed, however. Although most chemical reactions discriminate against the incorporation of deuterium and tritium in favor of hydrogen (5), it is conceivable that, for some biochemical reactions, the discrimination against tritium "leaving" a biochemical compound once it is incorporated might be greater than that for its "entering" the compound. This could in theory lead to a trapping or concentration factor. There are data indicating a concentration of deuterium in stable biochemical compounds such as honey and beeswax $(23 ; 25)$.

Even if such examples do represent a true trapping phenomenon, it is of no significance practically for the following reasons: Animal experiments involving chronic exposure to tritum under controlled conditions, such as those referred to above $(5-7,14-16,18)$, show a marked reverse phenomenon -the concentration of tritium in body tissues is clearly much lower than that in: the source of water. Also, man obviously does not receive all of his food and drink from sources having a uniformly high tritium concentration, and thus a large dilution factor results.

Thus at present, under practical conditions with respect to man, a positive concentration factor does not appear to exist, and a sizable fractional concentration factor applies. 
Possible Concentration of Tritium in the Food Chain. Although of little relevance to a short-term (months to years) exposure of man to tritium in the environment, the possibility of concentration should be considered under long-term (many decades) conditions in which addec tritium might begin to approach equilibrium in the entire biosphere. Since a trapping or concentration phenomenon in body organs was shown above to be of no practical significance in the mammal, concentration via the food chain would likewise be expected to be of no significance. The worst situation that can be visualized would be if all of the "building blocks" for biochemical molecules were obtained via the diet. Then the newly-formed molecules such as protein, RNA and DNA could have tritium specific activity approaching that in the dietary material. However, higher organisms, including man, also.synthesize their own building blocks, e.8.; purine and pyrimidine nucleotides, and are not dependent on preformed nucleotides derived from food. A large percentage of nucleic acid precursors given orally are broken down before absorption $(8,26)$. From these considerations the tritium specific activity in the biochemical molecules in people would approach that in the food they ingest under extreme condition only, and the expectation is that it would be far less under any practical conditions.

Some data indicate that transfer of HTO may be more efficient via one food chain route than another (27). Additional studies on the rates of movement of HTO in food chains are necessary.

HTO in DNA: Possible Additional Effect From. A possible additional effect of tritium disintegration, by virtue of the fact that the tritium may have been incorporated into organic molecules such as DNA, must be considered $(28,30)$. When tritium is disintegrated it becomes helium-3, 
which leaves an organic molecule that is positively charged. Some of these reactive organis ions may cause molecular rearrangement to occur, similar to the ions and radicals formed by ionizing radiation. Quantitatively, however, any biological effect is expected to be spall in comparison to that caused by the track of the beta ray which yields several hundred ions and radicals. Thus the effect, if it occurs, would be expected to be small.

Possible additional effects of $\mathrm{H}^{3}$ in DNA cannot be measured in biological systems using tritiated water, because of the small amount of incorporation of itium into organic molecules (most is in water). However, the possibility of such an effect can be studied under artificial laboratory conditions, which would not be encountered practically in the environment. It is possible to place tritiun selectively in various positions in $a$ number of organic molecules, which are incorporated selectively and in a known manner into macromolecules such as DNA and RNA. Examples are tritiated thymidine, which goes exclusively to DIA in the cell nucleus, م and tritiated cytidine which is incorporated into both DNA and RNA. A number of other examples could be cited. Because the compounds go selectively into macromolecules, there is a concentration of tritium in the cell nucleus. However, this of course bears no relationship to the situation in which tritium is ingested as tritiated water, as is the case with tritium in the environment.

By means of such selective localization of tritium in specific macromolecules, experiments can be done to determine if there are conditions in which an effect over and above that expected from the absorbed dose from the tritium beta rays can be detected. Such an effect has been looked for extensively with $\mathrm{H}^{3}$ TDR in mammalian biological systems 
(6-8), and over fifty pertinunt references were analyzed in detail. No additional effect was found.

To illustrate the problem more definitively, an example of the type of experiment that is critical is outlined: tritium as tritiated water is introduced in a single application into a biological system. It is ihus distributed essentially uniformly throughout the cell and its nucleus and delivers a uniform radiation dose from the beta rays of the tritium. Very rarely are tritium atoms incorporated into DNA or RNA under these circumstances. In a parallel experiment, tritium is given as tritiated thymidine that is incorporated only into DNA in the cell nucleus. Conditions are adjusted so that the cell nucleus receives the same radiation dose in rads in both cases, the only difference being that in.the one case the tritium is incorporated into DNA and not in the other. A11 experiments of this type to date, on somatic and genetic effects in mamma1s, showed approximately the same degree of biological effect whether or not the tritium was incorporated inco DNA, i.e., the tritium showed no significant additional effect by virtue of its having been incorporated into DNA (5-8). This might be expected, since the range of the tritium-beta track is very large compared to the width of a DNA molecule, and most of the energy would be expended outaide of the molecula.

Some experimente, however, have indicated that tritifum on one specific location in the pyrimidne ring may produce an effect in lower organisms that is in excess of that anticipated from the radiation dose from tritfum. These experiments were done with bacteria and with drosophila (31-33). Tritium deliberately placed in the five position in the 
pyrimidine ring did show an effect in excess of that expected trom the radiation dose alone. A similar effect was looked for with various other tritiated compounds, in which the tritium was located either in a different position on the pyrimidine ring, or in other precursors of DNA and RNA (31-33). No such effect has been found, i.e., the degree of effect was entirely that expected from the beta radiation of the tritium.

It is difficult to estimate the degree to which such an effect might increase the mutation rate over that expected from the beta radiation. One calculation indicates that the maximum increase might be of the order of 25 percent (34). Furthur work must be done, and it must be determined if an additional effect of $\mathrm{H}^{3}$ in the five position in the pyrimidine ring can be detected in the mammal.

The demonstration of an excess effect in lower organisms by virtue of the location of the tritium on the five position in the pyrimidine ring is of considerable scientific interest, but is of little practical import with respect to the toxicity of tritium encountered in the environment $(5-8,34)$. First, it is emphasized that the effect is seen at all only under highly specialized laboratory conditions in which great care is taken to insure that the tritium is incorporated, in Large concentrations, in a specific location on a specific ring in a specific compound. Under conditions in which tritium is encountered in the environment, only a small percentage is incorporated specifically into such organic compcunds under the "worst" conditions of equilibrium of the organism with the source of tritium in the environment. Of the small percent incorporated into all organic compounds, only a small 
percent of this can be incorporated into the five position on the pyrimidine ring. The overall conclusion is that under practical conditions in which tritium is ingested or inhaled as tritium water, the effect noted above would not add measureably to the effect of the tritium beta rays. That is to say, the degree of effect is to be predicted on the basis of the absorbed dose in rads (or the dose equivalent in rem), and there appears to be no reason for expecting significant additonal effects on the basis that some of the tritium may be incorporated into DNA or other biochemical molecules.

Mass Isotope Effect: Possible Toxicity From. Because tritium is heavier than ordinary hydrogen, the speed of reactions involving the exchange of tritium on a molecule will be different than for hydrogen. If large amounts of tritium relative to hydrogen are involved, biological consequences conceivably could result. It is known that deuterium, another heavy isotope of hydrogen, will lead to toxicity on this basis. However, very high concentrations of deuterium must be obtained ( a large fraction of all hydrogen atoms must be replaced by deuterium) before such an effect is seen (12).

In the case of tritium, such a possible effect is of no practical importance. Not only is the number of tritium molecules available in practice much too small, but in addition biological effects from radiation toxicity are encountered long before the necessary high concentrations are reached. Thus this potential factor can be dismissed as having no importance in biological systems.

Effects of Long-Turnover Compartments on Dose Calculations. As noted above, tritium may enter a number of body compartments with different 
times of excretion. These compartments in man may have half times of disappearance of approximateiy 6,23 and 345 days (19). The question arises as to whether the half disappearance time of 12 days; adopted by the NCRP and ICRP $(1,2)$ is adequate, and whether the presence of compartments with very long turnover times should be taken into account additiona11y.

Only the long-term chronic ingestion situation in man is pertinent to the present discussion. As shown above, with long-term exposure to tritiated water, the concentration of tritium in body water or in body tissues will not exceed that maintained in the intake food or water. Further, it was shown above that the biological effect depends principally on the total concentration of tritium in the cells and cell nuclei, and the degree of effect is not dependent on whether the tritium is bound to vater, or to other biochemical compounds including DNA. On this basis the presence of tritium in body compartments with a long-turnover time would have no significant influence on the calculated dose or on the degree of postulated biological effect.

The above question has been looked at in some detail (35), and it was asked if the assumption of the distribution of tritium as body water sexiously affects the estimate of absorbed radiation dose from this isotope. The conclusion was reached that the assumption of distribution with body water is conservative for acute cases in which the time of tritium exposure is known, and is also conservative for chronic assimilations of tritium.

Congervative Nature of ICRP Limits for Tritium. The NCRP-ICRP have 
established $1000 \mu \mathrm{Ci}$ as the maximum permissible body burden of tritium for occupational exposure with body tissue as the critical organ $(1,2)$. A value of $2000 \mu \mathrm{Ci}$ is also listed with the whole body as the critical organ. Since these figures have been widely misinterpreted, it may be well to explain how they were obtained.

If tritium is uniformly distributed throughout the body so that the ent.rgy released is absorbed by the entire $70 \mathrm{~kg}$ mass of a "standard man", $1960 \mu \mathrm{Ci}$ (about $2000 \mu \mathrm{Ci}$ ) of tritium will give a dose rate of $100 \mathrm{mrem} /$ week corresponding to the maximum permissible occupationai exposure of 5000 mrem/year. Since water and body tissues are intimately related this situation will apply approximately in practice eicher to the equilibrium case where all tissues have become labeled with tritium or tc an acute exposure situation where most of the tritium is in the aqueous fraction of the body (body water). In the equilibrium case the dose will vary slightly from tissue to tissue depending on the hydrogen content, but this variation is . small. When the tritium is confined to the body water, dose will vary with the water content of tissue and allowance has been made for this as explained in the next paragraph.

In setting the $1000 \mu \mathrm{Ci}$ limit when body tissue is the critical organ, the ICRP has taken note of the fact that the water content of tissues varies, with some tissues containing up to $80 \%$ water. This makes no significant difference for the equilibrium case since the hydrogen content of tissue and water are similar; but for the acute case where tritium is mostly in the body water, an organ with more water will receive a higher dose. To be conservative a hypothetical. organ consisting entirely of water was considered. Such an organ would receive the same dose rate as the $43 \mathrm{~kg}$ of 
body water undiluted by tissue. Computation shows that $1200 \mu \mathrm{Ci}$ will result in $100 \mathrm{mrem} /$ week for this limiting case. This was rounded off conservatively to $1000 \mu \mathrm{Ci}$ and used as the maximum permissible body burden. The $2000 \mu \mathrm{Ci}$ figure is published for use when considering the equilibrium situation or when combining dosage components to the whole body from more than one radionuclide. It should be noted that choice of $1000 \mu \mathrm{Ci}$ as the maximum permissible body burden does not imply a belief that tritium is confined to body water. Rather it results from a conservative approach aimed at keeping the dose rate to any tissue, even for a limited period of time, below $100 \mathrm{mrem} /$ week.

The $1000 \mu \mathrm{Ci}$ maximum permissible body burden recomended by the ICRP and used by AEC facilities is quite conservative. For long-tern exposures the exposure rate to the whole body will be only $50 \mathrm{mrem} / \mathrm{week}$, i.e., one half of the maximum permissible value. Since an. RBE of 1.7 has previously been used in the tritium computations, the most recent ICRP conclusion that an RBE of 1.0 is correct means that the dose rate is more properly deduced as 29 mrem/week or only $29 \%$ of maximum permissible. For short-term exposure, if one uses $80 \%$ instead of $100 \%$ as the water content of the critical tissue and an $R B E$ of 1 , one obtains a dose rate to this tissue of 39 mrem/week or $39 \%$ of macimum permissible. Here too, $1000 \mu \mathrm{CI}$ is conservative.

It should be noted that the ICRP has used the combined fintake of water in fluids (1200 ml) and in food (1000 ml), and a maximum permissible body burden of $1000 \mu \mathrm{Ci}$, in computing the maximum permissible value for water. Thus if intake is entirely in water, the equilibrium dose rate to the body will be $50 \times 12 / 22=27 \mathrm{mrem} /$ week (15 mrem/week for RBE = 1) or 
only about $1 / 4$ of maximum permissible. For the acute case, for a tisue with $80 \%$ water, and using an $\mathrm{RBE}=1$ the rate will be $39 \times 12 / 22=21$ mrem/week. Stated differently, the water limits in addition, to being based on conservative values of maximum permissible body burden, include an allowance for tritium in food. Under conditions in which one receives tritium essentially entirely from chronic ingestion of tritiated water, NCRP-ICRP calculations of the dose equivalent from MPC values for water lead to values that are conservative by a factor of bețween 5 and 8 . It is a general principal of internal dosimetry that all pathways contributing to the body burden must be counted. Thus the combined effect of tritium activity in air, water and non-aqueous components of food must be evaluated. Considering the conservative nature of the water limits and the substantial allowance for tritium in the water content of food, a separate limit for tritium in food is required only under very special circumstances.

Although the above analysis has been directed towards occupational exposure, the same conclusions apply to population exposure since the latter limits are established as specific fractions of the occupational values.

HTO Turnover in the Embryo; Possible Effects on the Fetus. Possible effects of tritiated water on the embryo have been studied under conditions in which very large amounts of tritiated water were administered to female rats during the 22 day gestation period, and the new born were examined with respect to tritium concentrations and biological effects (18). Concentrations of $1,10,50$ and $100 \mu \mathrm{c} / \mathrm{ml}$ of water resulted in total doses 
to the embryos of approximately 8, 60, 300 and 600 rads, respectively. No significant effects were cbserved at the $1 \mu \mathrm{c} / \mathrm{ml}$ level. At the $10 \mu / \mathrm{ml}$ level significant differences were reported for the the male testes, the kidney and the brain. Results were expressed in terms of percent body weight. If results are expressed in terms of absolute weights of organs, differences in any organ weight except that of the testes at doses below approximately $50 \mu \mathrm{c} / \mathrm{ml}(300 \mathrm{rads}$ ). are of questionable significance:

The above results are consistent with those obtained by others with external $x$ - or gamma radiation, namely that doses in the range of tens of rads and above to the fetus can produce observable changes of this type in the new born (37). Thus radiation from tritium appears to act as expected on the basis of absorbed dose, and there is no reason to postulate any unusual effect by virtue of the fact that radiation was derived from tritium. Also, it should be pointed out that effects such as differences in brain weight undoubtedly result from damage to a large number of cells. On this basis the dose-effect curve for such a result would be expected to be markedly curvilinear, i.e. the effect per rad would fall off very rapidly as the dose is reduced. On this basis, one would not expect to find changes of this nature even in very large populations exposed to doses of the ordex of millirads or a few rads.

Additonal laboratory studies have been done (38), in which tritiated thymidine was given to female rats throughout pregnancy. Under these conditions the tritium is located essentially entirely in DNA, and the nucleus of every cell of the newborn is labeled as determined by autoradiography. Large doses of trj.tiated thymine were used; extensive 
studies were done at the level of $1.6 \mu \mathrm{\mu c}$ of tritiated thymidine per gram of body weight. Even under these extreme conditions, 1.e., high dose, essentially all tritium in DNA, there was atc increase in the incidence of abnorinal off-spring over that in controls. It was concluded that while some effect could not be excluded, it was small indeed if present. No increase in the number of chromosome abnormalities in the cells of the newborn was found.

HTO in Embryo; Possible Genetic Effects. It has been pointed out that tritium incorporated into the female fetus might be somewhat more hazardous in terms of possible genetic effects in the germ cells of the adult developing from the fetus exposed in utero $(29,30)$. All tissues in the growing embryo are developing, and all cells within these tisuues undergo division and synthesize DNA. In many tissues such as the bone marrow, the skin and the epithelium of the bowel, the cells continue to divide after the fetus is born, and throughout adult life. In some tissues however, such as the brain, muscle, the liver, and the ovary, the cells cease to divide at birth or during early development. It is thus possible that in these tissues some tritium might become "fixed" in compounds such as DNA during embryogenesis, and would remain there essentially throughout adult life. That this probably has little significance beyond that expected from the dose or dose equivalent to the oocytes received from tritium or any otiner radiation is shown below. Both the male and female fetus are considered.

With respect to the male fetus, the germ cells of the testes divide during embryogenesis and continue to divide throughout the adult life of the individual. In the adult an approximate steady state cellular equilibrium 
exists, i.e., for every new germ cell produced in the gonads, on the average one cell (and any tritium in that cell) is eliminated from the body. New tritium would be incorporated into newly-formed cells only under conditions of new or continuous exposure to tritium. The nost important point, however, is that, as shown above, the potential effect depends on the total dose of radiation from tritium in the cells and cell nuclei, and that it makes little difference whether the tritium be in the form of water or in organic compounds including DNA.

With respect to the oxytes in the female, the situation is similar in many respects. Of the total amount of tritium that might be present in the oocytes or in any other cell, only a very small fraction would be int DNA. A very large percentage of any dose that might be received from tritium would come from tritium in water and in compounds other than DNA. Again, as shown above, the effects are dependent on the total amount of tritium in the cell and cell nucleus, and essentially independent of the relative amounts that may be in any particular biochemical compartment, including DNA. In addition, it has been shown (39) that the apparent degree of recovery from genetic damage from ionizing radiation in the female mouse is enormous and that recovery may be essentially complete, i.e., a threshold situation may pertain for all practical purposes. On these bases, there would appear to be no reason at present to regard tritium in the female embryo as posing an unusual hazard. In other words, if a given dose or cose equivalent is received by the oocytes, either from the beta rays of tritium, from external x-rays or from the gamma rays from any isotope, the degree of potential effect is the same and there appears 
to be no reason at present for postulating a significantly greater degree of effect by virtue of the fact that the radiation dose may have been received from tritium,

Dose to the Population form Reactor-produced Tritium. Since it

has been shown avove that the degree of potential hazard from tritium radiation is adequately and conservatively represented by the calculated dose in millirem, it is appropriate to consider estimates of the dose of radiation that the population may receive from tritium released by power reactors. Since presumably large populations, or the entire population of a country or the world may be exposed, possible genetic effects in the population would appear to be the potential effect of most importance. With respect to genetic effects, it is the average dose to the population that is of most significance, i.e., it makes little difference with respect to genetic effects whether one individual receives 100 units of radiation exposire, or 100 individuals receive 1 unit of radiation exposure.

The probable dose to the population from tritium has been calculated for the year $2000(40,41)$ assuming that power reactors will continue to be installed and operated at the current rate. The average dose to the population from tritium is estimated to be a small fraction of a millirem per year, 0.001 millirems to be precisa (41). This value compares with: current exposure to naturally and weapons-testing produced tritium of the order of $0.1 \mathrm{mrem} /$ year $(42,43)$; an estimated $1-2$ millirem that may be received in crossing the United States in a jet; the several millirem additional that may be received in going from the shore to spend a few days at a skiing retreat in the mountains; the approximately 100 or more millirem that one may receive per year by virtue of living in a concrete 
versus a wooden structure; and the average of some 120 milizem from natural background radiation that the population of the United States receives on the average per year. Thus expsoure of the population to tritium from power reactors does not represent a significant additional exposure to the population, additionally when it is kept in mind that the estimates for tritium exposure (41) were made on the basis of formulae provided by the ICRP which were shown above to be conservative by a sizeable factor.

With respect to possible exposure to tritium of local populations near a factor located on a body of water, a specific situation has been considered (44). The dose rate to the local population, if the sole source of drinking water were derived from this source, is estimated to be 0.003 millirads per year. As indicated above, dose rates of this order of magnitude do not represent a significant additonal expsoure to even very large populations.

Summary and Conclusions. The possible biological effects of tritium have been analyzed, and several factors that must go into an evaluation have been considered both from the theoretical and experimental standpoints. . Maximum permissible concentrations or maximum permissible doses of tritium are based principally on the absorbed radiation dose delivered by the tritium beta rays. Several possible factors that might possibly increase the degree of toxicity over that expected from the absorbed dose are considered in some detail. These include the possibility of concentration of tritium, and the possibility of concentration of tritium, and the possibility of additional toxicity by virtue of the fact that some tritium may be 
incorporated into biological molecules such as DNA. The conclusion is reached that these factors do not significantly increase the dose that might be expected from a given concentration of tritium in the envitonment, or the effects of that dose. A given dose $(\mathrm{g.g.,}$ an MPD) of radiation from the beta rays of tritiun (fxom either inhalation or ingestion) has the same radiobiological and radiation protection meaning as the given dose from x-rays or gamma rays (same dose race pattern), and no added significance or potential hazard is to be attached by virtue of the fact that the dose may have been derived from tritium. Calculated population expsure from reactor-produced HTO is very small, compared to that from natural and weapons-testing produced HTO, and from other sources of radiation to which the population is exposed.

Note: The author is indebted to F. Cowan, A. Hull, and C. Meinhold for for helpful discussions during the preparation of this material. 
1. Report of ICRP Committee II on Permissible Dose for Internal Radiation, Health Phys. $\underline{3}$ (1960) 1-380.

2. NCRP report, Handbook 69, Maximum Permissible Body Burdens and Maximum Permissible Concentrations of Radionuclides in Air and in Water for Occouaptional Exposure, U. S. Department of Commerce, U. S. Gov't. Printing Gefice (1959).

3. HARDEK, D. Spectra of Primary and Secondary Electrons in Material Irradiated by Fast Electrons. In Biophysical Aspects of Radiation Quality, IAEA Publ. Tech. Report Serieg $58(1966)$.

4. ZERMENO, A. and COLE, A. Radiosensitive Structure of Metaphase and Interphase Hamster Cells as Studied by Low-Voltage Electron Beam Irradiation, Rad. Res. 39 (1969) 669-684.

5. FEINENDEgEN, L. E. Tritium-labeled Molecules in Biology and Medicine, Acad. Press, New York and London.(1967).

6. BOND, Y. P. and FEINENDEGEN, I. F. Intranuclear ${ }^{3}$ H Thymidine: Dosimetric Radiological and Radiation Protection Aspects, H1th. Phys. 12 (1966) 1007-1020.

7. VENNART, J. Radiotoxicity of Tritium and ${ }^{14} \mathrm{C}$ Compounds, H1th. Phys. 16 (1969) 429-440.

8. ROBISON, W. L. and ANSPAUGH, L. R. Blological Hazards from Project Rulison, Livermore, Calif. Draft Report.

9. SHTUKKENBERG, Y. M. Application of Tritium in Biological Research, U. N. Scientific Commictee on Effects of Atomic Radiation, A/AC, 82/G,L. 552 (1960).

10. LAMBERT, B. E. Cytological Damage Produced in the Mouse Testes by Tritiated Thymidine, Tritiated Water and X-rays, H1th. Phys. 17 (1969) 547 .

11. SNYDER, W. S. Personal Communication.

12. SIRI, W. F. and EVER, J. Tritium Exchange in Biological Systems, in Tritium in Biological systems, Symp. IAEA 2 (1961) 71-84.

13. RITTENBERG, D. The Effect of Isotopic Substitution in the Living Cell, J. of Chem. Phys., 60 (1963) 318-322.

14. THOMPSON, R. C, and BALLOU; J. E. Studies of Metabolic Turnover with Tritium as a Tracer, V., J. of Blology and Chem. 223 (1956) 795-809.

15. PINSON, E. and LANGHAM, W. Physiology and Toxicology of Tritium In Man, J. Appi. Physiol. 10 (1957) 108-126.

16. KHAN, A. A. and WILSON, J. E. Studies of Turnover in Mammailan Subcellular Particles: Brain Nuclei, Mitochondria and Microsomea, Neurochem. 12 (1965) 81-86, Perg. Press, N. Ireland. 
17. METZGER, H. P. The Effect of Unilateral Visual Stimulation on Synthesis of Cortical Proteins in Each Hemisphere of the Split-Brain Monkey, J. Neurochem. 114 (1967) 183-187.

18. CAHILL, D. F, and YUILE, C. L. Some Efiects of Tritiated Water on Mammalian Fetal Development, Rochester, New York, Draft Report.

19. REINIG, W. C. and SANDERS, S. M. (Jr.) Assessment of Tritium in Man, Presented at Symp. on Diagnosis and Treatment of Deposited Radionuclides, May 15-17, 1967, Richland, Washing-. ton, for Publication in Symp. Proceed. by Excerpta Medica.

20. SNYDER, W. S. Urinary Excretion of Tritium following Exposure of Man to HTo - - a Two Exponential Model, Phys. Med. Biol., Vol. 13, No. 4 (1968) 547-559.

21. SHORE, B. The Fate and Importance of Radionuclides Produced in Plowshare Events (preprint). Prepared for submittal to the U. S. Public Health Symp, Las Vegas, Nevada, April 7-11, 1969 .

22. EVANS, A. G. New Dose Estimates from Chronic Tritium Exposures, Health Phys. 16 (1969) 57-63, Pergamon Press, N. Ireland.

23. BOWEN, J. J. M. Trace Elements in Biochemistry. Biologic Fractionation of Isotopes, Academic Press, London (1966) 137-139.

24. HELVEY, T. C. The National Concentration of Deuterium in Honey, Science 117 (1953) 276-277.

25. KRAICHEVSKY'M. I., FRIEDMAN, I., NEWALL, M. F., and SISLAR, F. D. Deuterium Fractionation during Molecular Hydrogen Formation in a Marine Pseudomonad. J. Biol. Chem. 236 (1961) 2520 .

26. WADE, L. (Jr.) and SHAW, E. I. Preliminary Estimate of the Hazard from Ingestion of Tritiated Thymidine, Lawrence, Kansas, $\mathrm{D}$ aft Report.

27. KIRCHMAN, R. and VAN DEN HOCK, J. Transfer et Incorporation du tritium dans les Constituants de l'Herbe et du lait, en Conditions Naturelles, International Radiation Protection Association meeting, 3-8 May 1970, Brighton, England.

28. HUVER, C. W. Biological Effects of Tritium, Presented to Mínnesota Polution Control Agency, February 19, 1969.

29. RADFORD, E. P. Teatimony before the Subcommittee on Air and Water Polution of the Committee on Public Works, November 19, 1969, Washington, D.C. S3042, 96-183. 
30. RADFORD, E. P., MERZ, T., RAY, C., HERRIOT, R. M., KRUSE, C. W., SOUTHWICK, C. H. AND SLADEN, B. K. Statement of Concern, Environment, 11 (1969) 18-27.

31. PERSON, S. Lethal and Mutagenic Effects of Tritium Decay Produced by Tritiated Compounds Incorporated into Bacteria and Bacteriophages. In, Symp. Report, Biological Effects of Transmutation and Decay of Incorporated Radioisotopes, IAEA, Vienna, (1968).

32. FUNK, F., PERSON, S.3 Cytosine to Thymine Transitions from Decay of Cytosine-5- ${ }^{H}$ in Bacteriophage S 13 , Science 166 (1969) 1629-1631.

33. KIEFT, P. Induction of Recessive Lethals by ${ }^{3} H$ Uriáine and H Thymidine in Drosophila. In, Symp. Report, Biological Effects of Transmutation and Decay of Incorporated Radioisotopes, I.A.E.A., Vienna (1968).

34. PERSON, S. Personal Communication.

35. SANDERS, S. M. (Jr.) Dose Estimates from Chronic and Acute Tritium Exposures, Draft Report.

36. CAHILL, D. F. Personal Communication.

37. United Nations Scientifis Committee on the Effects of Atomic Radiation, Report of General Assembly, 17 th Session, Supp 1. 16, A/5216 (1962).

38. FLIEDNER, T. M., HAAS, R. J., STEHLE, H. ARD ADAMS, A. Gomplete Labeling of all Cell Nuclei in Newborn Rats with H-Thymidine, Lab. Investigation 18 (1968) 249-259.

39. RUSSELL, W. L. Factors that Affect the Radiation Induction of Mutatrons in the Mouse, Annals of the Brazilian Acad. of Sciences 39 (1967) 65-75.

40. PETERSON, H. T. (Jr.) Environmental Tritium Contamination from Increasing Utilization of Nuclear Energy Sources, Presented at Seminar on Agricultural and Public Health Aspects of Environmental Contamination by Radioactive Materials, Vienna, Austria March 24-28, 1969.

41. JACOBS, D. G. Sources of Tritium and its Behavior Upon Release to the Environment. In, Hearings of the Joint Committee on Atomic Energy, Part I, October 28 - November 7 , 1969,500 .

42. THOMPSON, T. J. Testimony on "Environmental Effects of Producing Electrical Power". Joint Committee on Atomic Energy, October 30, 1969 .

43. MOGHISSI, A. A, and LIEBERMAN, R. Tritium Body Bucden of Children, 1967-68. Radiol. Health Data and Reporta 1 I (1970) 227-231. 
44. AEC Comments on Tritium Releases from the Proposed Calvert Cliffs Nuclear Power Plant. In, Selected Materials on Environmental Effects of Producing Electric Power, Joint Committee on Atomic Energy, 918 t Congress (1969) 507. 